\title{
Reason for HIV Patients Consultation to the Emergency Department in the HAART Era: Incidence and Mortality
}

\author{
Camón S1, Perelló $\mathbf{R}^{1 *}$, Escoda $\mathbf{O}^{1}$, Escoda $\mathbf{R}^{1}$, Aguilar $\mathbf{N}^{1}$, Saubí $\mathbf{N}^{2}$, López $\mathrm{C}^{1}$, Quirós $\mathrm{C}^{1}$, Company $\mathbf{A}^{1}$, Castañeda $\mathbf{M}^{1}$ and Martínez $\mathrm{E}^{2}$
}

${ }^{1}$ Emergency Service, Hospital Clínic, Research Group "ER: Processes and Pathologies", IDIBAPS, Barcelona, Spain

${ }^{2}$ Department of Infectious Diseases, Hospital Clínic, IDIBAPS, University of Barcelona, Spain

\begin{abstract}
Aim: To describe the, incidence, the changes in the etiology and the prognosis of HIV infected patients, presenting by the first time to the Emergency Department (ED), during years 2000-2010.
\end{abstract}

Study Design: Retrospective collection of data.

Methods: The identification of patients was carried out by consulting, retrospectively, the medical records, of the patients that flocked to ED, by any pathology, in appreciating the diagnosis and known HIV or diagnosed during their hospital admission. Patients referred from other hospitals that had previously been visited at their ED or consultations after the first visit were excluded. Epidemiological and laboratory data were analyzed as well as, the influence of these variables on a 30 days mortality test was analyzed. Poor prognosis was defined by observing mortality at 30 days.

Results: A total of 445 HIV patients were included in the study. The mean age was $40.92 \pm 10$ years. The infectious disease was the most frequent cause of visits to the ED. Neurological affectation was the most common cause of consultation due to non-infectious diseases. The incidence of HIV patients reported to the ED had been declining in the last decade, with a maximum peak inflow in 2001 of 41.21 patients/year. The overall mortality in the study was $8 \%$. Logistic regression analysis showed that admission to ICU $(p<0.001)$ was independent variables predicting mortality.

Conclusion. Infectious disease is the most common cause of HIV patient consultation at the ED, with a decreasing incidence, probably related to the widespread utilization increased of HAART. Our results may serve as a benchmark reference to other Spanish centers.

Keywords: Emergency Department; HIV; HAART

\section{Introduction}

The main role of Emergency Departments (ED) is to respond to the urgent health needs of the population by offering not only effective, efficient and equitable assistance, but also of high quality [1]. ED is the gateway to the highest flow of patients to hospitals and, specifically, they are the most commonly used for medical care by the population infected with the human immunodeficiency virus (HIV) [2]. In the mid- $90 \mathrm{~s}$, with the introduction of new antiretroviral therapy (HAART), HIV patients have undergone a great change in their quality of life, with a decrease in morbidity and mortality [3] and a decrease of AIDS cases [4]. This has led to the emergence of non-infectious diseases in HIV patients that until now were more predominant in the general population, such as ischemic heart disease, oncological pathology, neurological diseases [5-7], etc. These non-infectious diseases were not previously diagnosed in the HIV patients, most probably, because these patients died before developing them. These new events may lead in the future to more ED professional healthcare workers and to a more realiable diagnostics tests and treatments [8].

Althoughthemortality fromHIVhasexperiencedamarked reduction with the introduction of new treatments and better prevention policies [9], HIV infection prevalence is still very high and represents a major global socioeconomic impact, since increased mortality is observed in young people, mostly between 35 to 44 years old group. In 2008, HIV infection represented in this group the second leading cause of death in men (419 deaths) and fourth in women (122 deaths) in our country [10]. The vast majority of studies on HIV patients and ED refers to the rapid HIV diagnostic tests and their applicability in the ED [11-13]. Thus, very few studies have been carried out on determining the reasons of HIV patients for consulting an ED, the mortality rates and their incidence in the HAART era. Therefore, we aimed to perform such a study in order to improve the existing prevention policies and greater professionalization of ED personal.

\section{Patients and Materials}

A 10 year retrospective study (2000-2010) made in Our Center that is a tertiary university hospital assisting an area of 500,000 inhabitants, with around 125,000 total consultations to the ED and 42,000 medical emergencies per year [14]. The HIV patients that monitor our outpatient's services are around 5,000. This study was approved by the Ethics Committee of the Hospital.

The identification of patients was carried out by consulting, retrospectively, the medical records by doctors and nurses of ED staff, of the patients that flocked to ED, by any pathology, in appreciating the diagnosis and known HIV or diagnosed during their hospital admission. Patients referred from other hospitals that had previously been visited at their ED or consultations after the first visit were excluded.

To assign the reason of consultation, the medical record was

*Corresponding author: Rafael Perelló, Servicio de Urgencias. Hospital Clínic, Villarroel 170, 08036 Barcelona, Spain, Tel: +3493 2279833; E-mail: rperello@clinic.ub.es

Received June 20, 2014; Accepted August 26, 2014; Published September 05, 2014

Citation: Camón S, Perelló R, Escoda O, Escoda R, Aguilar N, et al. (2014) Reason for HIV Patients Consultation to the Emergency Department in the HAART Era: Incidence and Mortality. J AIDS Clin Res 5: 340. doi:10.4172/2155-6113.1000340

Copyright: (C) 2014 Camón S, et al. This is an open-access article distributed under the terms of the Creative Commons Attribution License, which permits unrestricted use, distribution, and reproduction in any medium, provided the original author and source are credited. 


\begin{tabular}{|c|c|c|c|c|c|}
\hline Variable & Total cohort $(n=445)$ & $\begin{array}{c}\text { AIDS } \\
(n=230)\end{array}$ & No AIDS $(n=215)$ & Statistic value & $P$ value \\
\hline Male (\%) & $330(74.2 \%)$ & $167(72.6 \%)$ & $163(75.8 \%)$ & $0.440^{1}$ & 0.507 \\
\hline Age (years) & $40.92 \pm 10.1$ & $39.84 \pm 9.76$ & $42.08 \pm 10.3$ & $-2.357^{2}$ & 0.019 \\
\hline Viral load ( $n^{\circ}$ copies) & $312673.15 \pm 5.77$ & $368665.49 \pm 5.055$ & $64599.73 \pm 2.34$ & $7.467^{2}$ & $<0.001$ \\
\hline CD4 lymphocytes & $272.90 \pm 286.46$ & $138.25 \pm 167.8$ & $423.25 \pm 315.68$ & $-10.820^{2}$ & $<0.001$ \\
\hline HAART (\%) & $236(53 \%)$ & $71(30.9 \%)$ & $165(76.7 \%)$ & $92.056^{1}$ & $<0.001$ \\
\hline Mortality at 30 days (\%) & $37(8.3 \%)$ & $28(12.2 \%)$ & $9(4.2 \%)$ & $8.283^{1}$ & 0.004 \\
\hline ICU admission & $64(14.4 \%)$ & $32(13.9 \%)$ & $32(14.9 \%)$ & $10.054^{1}$ & 0.007 \\
\hline
\end{tabular}

${ }^{1}$ Chi-square value. ${ }^{2} \mathrm{~T}$-test value

Table 1: Descriptive analysis of the HIV population.

\begin{tabular}{|c|c|c|}
\hline Diseases & Frequency & Percentage (\%) \\
\hline Respiratory infection & 135 & 30.3 \\
\hline Neurologiccal disease & 37 & 8.3 \\
\hline Fever & 33 & 7.4 \\
\hline SNC infection & 22 & 4.9 \\
\hline Osteomuscular disease & 22 & 4.9 \\
\hline Digestive disease & 21 & 4.7 \\
\hline Abdominal infection & 20 & 4.5 \\
\hline Liver disease & 19 & 4.3 \\
\hline Cardiovascular disease & 18 & 4.0 \\
\hline Dermatological disease & 18 & 4.0 \\
\hline Hematological disease & 17 & 3.8 \\
\hline Oncologic disease & 10 & 2.2 \\
\hline Constitutional syndrom & 10 & 2.2 \\
\hline Kidney infection & 8 & 1.8 \\
\hline Surgery & 7 & 1.6 \\
\hline Pulmonary disease & 6 & 1.3 \\
\hline Vascular disease & 6 & 1.3 \\
\hline Lymphadenopathy & 6 & 1.3 \\
\hline Bone infection & 5 & 1.1 \\
\hline Psychiatric illness & 5 & 1.1 \\
\hline Gynecological disease & 4 & 0.9 \\
\hline Kidney disease & 4 & 0.9 \\
\hline Endocarditis & 4 & 0.9 \\
\hline Endocrinological disease & 3 & 0.7 \\
\hline Ophthalmological disease & 3 & 0.7 \\
\hline Drugs overdose & 2 & 0.4 \\
\hline TOTAL & 445 & 100 \\
\hline
\end{tabular}

Table 2: Reason for visit of the ED population HIV.

categorized either by the target organ or, in the absence of symptomatic localization, by the presence of general symptoms. In addition, the presumptive diagnosis made during the patient's stay in the ED was also taken into account.

Epidemiological and laboratory data such as age, sex, HAART, CD4 and viral load (VL) were analyzed. We also determined whether the patients met the criteria for AIDS and their need for admission to the intensive care unit (ICU). In our center, the indications for the admission in the ICU are: the requirement of vasoactive support or the need of either invasive or noninvasive mechanical ventilation. Finally, the influence of these variables on a 30-days mortality test was analyzed. Poor prognosis was defined by observing mortality at 30 days.

To calculate HIV patient's incidence to ED (infected patients x1000 $\mathrm{HIV} /$ year), HIV patients monitored in other centers were not included in our study. The criteria for AIDS were implemented based on the recommendations from CDC [15].
Categorical variables were expressed as frequencies and percentages. All continuous variables were expressed as mean \pm standard deviation. Depending on the variable distribution, differences between groups were assessed by using either the parametric test (Chi- square and t-student) or the non-parametric test (Fisher's exact test). Stepwise logistic regression analysis was performed to model the relationship between mortality and each of the variables, including sex and age as potential confounders. A bilateral value of $p<0.05$ was considered significant. All statistical analysis was performed by using SPSS version 18.0 (Chicago, IL, USA).

\section{Results}

A total of 445 HIV patients were included in the study. The mean age was $40.92 \pm 10$ years. $74 \%$ of the patients were male, $52 \%$ meeting criteria for AIDS. $14 \%$ required admission to the ICU. As for the comparison of variables between patients with or without AIDS, the AIDS group showed increased mortality rates with higher ICU admissions (Table 1). The incidence of HIV patients reported to the ED has been declining in the last decade, with a maximum peak inflow in 2001 of 41.21 patients/year. Infectious disease was the most common cause of visits to the ED with a $55 \%$ of the patients. Among them, respiratory pathology was the main cause observed followed by the fever syndrome (once the battery of diagnostic tests was complete, we observed that all were caused by infection). We detected neurological involvement in $8 \%$ of the patients, which was the most frequent cause of non-infectious disease consultation (Table 2).

The incidence of HIV patients reported to the ED had been declining in the last decade, with a maximum peak inflow in 2001 of 41.21 patients/year (Figure 1).

The overall mortality in the study/series was $8 \%$, mainly due to

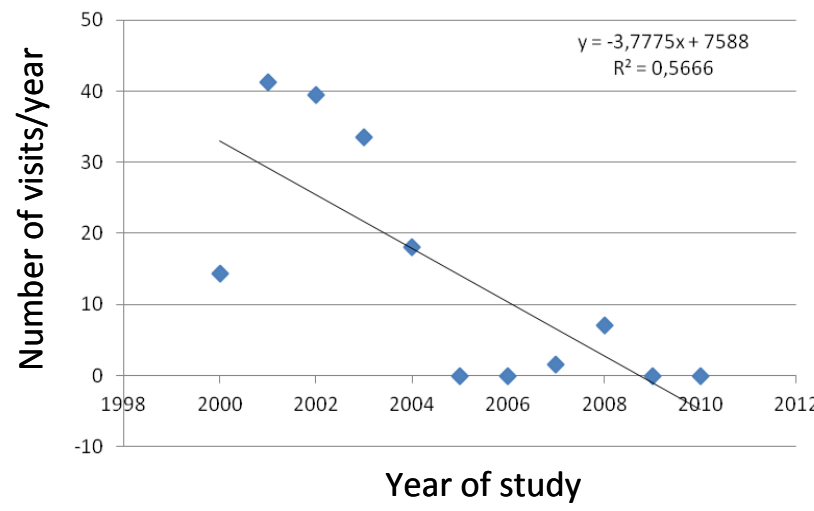

Figure 1: Incidence of HIV patients consulting the ED. 
infectious diseases. The respiratory pathology was the most commonly detected, followed by complications from chronic liver disease. Most deaths occurred in the ICU and were due to respiratory infections, presenting as sepsis or septic shock immediate complications. All patients admitted to the UCI, pointed vasoactive drugs.

Regarding the comparative study of patients who die or not (Table 3 ) in the first 30 days, patients without HAART treatment who meet AIDS criteria and are admitted to the ICU showed increased mortality $(\mathrm{p}<0.003, \mathrm{p}<0.002$ and $\mathrm{p}<0.001$, respectively) in the univariate analysis. However, the logistic regression analysis that included the other variables such as age, reason for consultation, viral load, ICU admission, TARGA, sex and AIDS, showed that the only variable that predicted 30 days mortality was the requirement of admission to the ICU $(\mathrm{p}<0.001$, $\exp (B)=14.41$, CI $95 \% 5.30$ to 38.66). The survival curves for 30 days are represented in Figures 2 and 3.

\section{Discussion}

Our work shows that the main reason for a HIV patient to visit an ED was mainly due to infectious (in 55\% of the cases) [16] over noninfectious diseases. This rate can be explained because many of our patients were not receiving HAART (by voluntary abandonment in most of the cases). In addition, $52 \%$ of the patients also met AIDS criteria, so they were more susceptible to sicken more frequently.

Noninfectious diseases are a significant cause of morbidity and mortality in patients newly diagnosed with HIV infection. Masiá et al. [17] suggest a protective effect of antiretroviral therapy in the occurrence of these events.

\begin{tabular}{|l|c|c|c|}
\hline Variables & \multicolumn{2}{|c|}{ Mortality at 30 days } & \\
\hline Male (\%) & Yes $(\mathrm{n}=37)$ & No $(\mathrm{n}=408)$ & $p$ \\
\hline Age (years) & $26(70.3 \%)$ & $304(74.5 \%)$ & 0.573 \\
\hline $\begin{array}{l}\text { Viral load (no } \\
\text { copies) }\end{array}$ & $43.62 \pm 10.21$ & $40.68 \pm 10.03$ & 0.071 \\
\hline CD4 lymphocytes & $336.10 \pm 244.68$ & $276.89 \pm 289.71$ & 0.116 \\
\hline HAART (\%) & $11(29.7 \%)$ & $225(55.1 \%)$ & 0.287 \\
\hline AIDS & $28(75.7 \%)$ & $202(49.5 \%)$ & 0.003 \\
\hline ICU admission & $23(62.2 \%)$ & $41(10 \%)$ & $<0.001$ \\
\hline \multicolumn{4}{|l|}{ Table 3: Analysis of mortality at 30 days. } \\
\hline
\end{tabular}

Survival Function

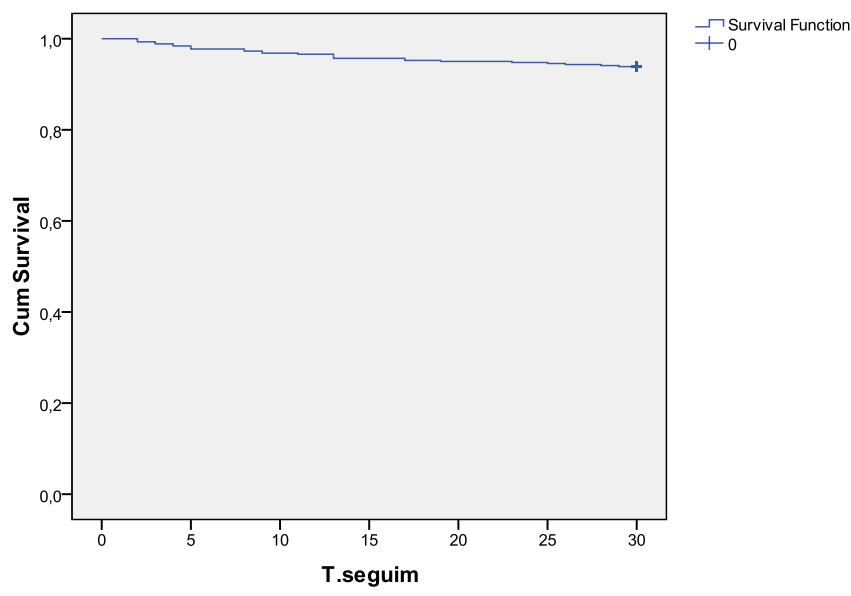

Figure 2 : Survival curve to 30 days for the entire cohort.

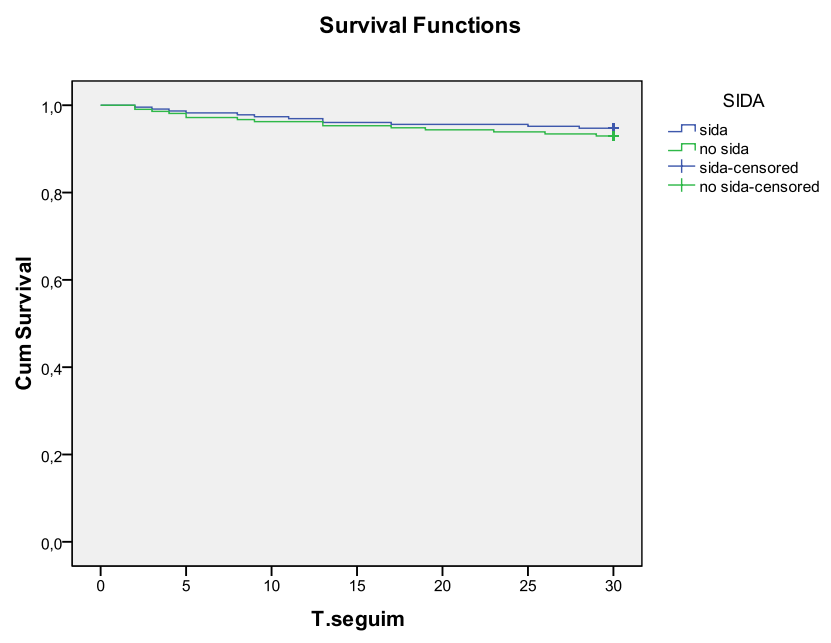

Figure 3: Survival curves to 30 days for the patients with AIDS.

Respiratory infection is the first cause among infectious diseases (and also overall). Pneumonia acquired in the community remains one of the major causes of deaths from infectious etiology, both in the general population and in HIV-infected patients [18]. Hence, knowing its incidence and the most common etiology is of particular importance. Although the febrile syndrome was the second leading cause of infectious etiology and the third leading cause of all emergency consultation cases. This was not related to a higher mortality in HIV patients (just one case), but implied a longer hospital stay and higher costs, given the large number of diagnostic tests required since the diagnostic range for fever etiologies in the HIV patients is very broad [19].

In our study, the central nervous system pathology, attributed to non-infectious etiology (mainly due to brain stroke), was the second leading cause of HIV patients consultation to our ED (8.3\%). Brain ischemic stroke has become a particularly significant neurological complication of HIV patients. This fact is of particular importance because these patients become chronic, resulting in an aging population together with the cardiovascular risk factors and the systemic endothelial inflammation that the HIV itself produces [20].

The involvement of cardiovascular and proper vascular affectation, basically ischemic heart disease and deep venous thrombosis, are also important in terms of frequency of visits to our ED (4\% and $1.3 \%$, respectively). It is already described that HIV patients show increased prothrombotic state and inflammation that result in increased hypercoagulability [21]. We should probably consider introducing antiplatelet prophylaxis to all HIV patients treated with HAART (except the haemophiliac group) together with a better control of cardiovascular risk factors, with the goal of preventing thrombotic events and reduce the number of neurological, cardiovascular ischemic events and intrauterine growth in HIV pregnant patients [22,23].

Although HAART was already widespread during our study (20002010), the total number of HIV patients that attended to the ED was small and declining over time [24]. HIV incidence has been declining in the last decade, it was a major cause of morbidity and mortality, and our results are consistent with previous studies [25].This decreased incidence is explained by the immunological recovery delivered by the HAART treatment that showed increased pharmacological potency and a higher patient compliance, also the availability of a specific daycare 
center in our hospital with higher personal and technological resources, it has become possible to treat some uncomplicated infectious without to referral to the ED. Nevertheless, HIV incidence is still higher in the general population, which parallels higher consumption of medical resources [26]. These results, the result of a good health policy at hospital level, in stark contrast to Spain increased each year between 3000 and 4000 new cases of HIV infection, yielding an annual incidence rate that exceeds the average of the European Union [27] that would indicate a failure of health policy primary prevention.

In the HIV area, most of the studies have been conducted in the USA, where the HIV patient care in the ED costs $\$ 100$ per year [28] and shows higher rates of ED use with greater consumption of resources than the general population $[29,30]$. This higher cost is attributable to the medication administered during the visit [31]. These studies from the USA are conducted in a completely different healthcare environment than ours, with theirs showing more difficulty of accessing to the HAART for free and limited social policies for reintegration. Thus, HIV patients who most frequently attend the ED in the USA are homeless people and drug abusers [32]. We were not able to test this last subject in our study. Therefore, although we cannot rule out such possibility, we cannot draw definitive conclusions from our work.

The overall mortality in our study was $8 \%$, which was higher in patients with AIDS and those who required ICU admission. $62 \%$ of the success occurred in the ICU. The infectious etiology was the leading cause of death with $59 \%$ of the cases ( $46 \%$ being due to respiratory pathology), followed by infection of the central nervous system and the abdominal cavity.

The second cause of death ( $16 \%$ of the cases) was due to liver affectation (mainly gastrointestinal bleeding) in HIV patients coinfected with HCV. HCV infection in these patients was most probably so high that these patients did not receive new HCV treatments, which would have led to a decrease in the mortality of these patients [33].

Finally, we have come a long way regarding the early HIV detection methods, the simplification of the collection and processing of samples [34], as well as the effectiveness of rapid HIV detection tests [35]. Therefore, providing ED specific protocols to properly face HIV patients is of vital importance, since many visits may be prevented by a good HAART compliance, a better healthcare education and a better understanding of the non-emergency healthcare resources that the healthcare system makes available to the user. Furthermore, a better monitoring of the causes of HAART rejection, such as low sociocultural level, higher prevalence of opiate addiction, and increased psychological distress [36] may also help to a better control of these patients. Meanwhile, a regular review analysis of HIV patients visits to the $\mathrm{ED}$, as well as the review of other quality care indices [37,38], may be a useful tool for monitoring the outcome of policies set to improve medical care in these patients [39]. In addition, this may also help to prevent future events and even suggest alternatives to conventional hospitalization (provided that the patient's condition permits) and, thus, leading to a reduction of the economic costs [40].

Our study has a series of limitations as it was conducted in a single hospital, although our hospital is one of the most important healthcare centers in Spain, not only in terms of number of HIV patients in followup but also in terms of emergency visits volume. Despite this limitation, the sample is large enough to draw some valid conclusions. The specific daycare center in our hospital lets try to treat some uncomplicated pathologies without to referral to the ED.

\section{Conclusion}

The infectious diseases are the most common cause of HIV patient consultation today. The respiratory pathology is the first cause among them. Our work shows specific data in our environment that can serve as a benchmark for other hospitals.

\section{References}

1. Miró O, Jiménez S, Alsina C, Javier Tovillas-Morán F, Sánchez M, et al. (1999) Unscheduled revisits in medical emergency units at the hospital: incidence and related factors. Med Clin (Barc) 112: 610-615.

2. Shih TY, Chen KF, Rothman RE, Hsieh YH (2011) US national estimation of emergency department utilization by patients given 'HIV/AIDS-related illness' as their primary diagnosis. HIV Med 12: 343-351.

3. Crum NF, Riffenburgh RH, Wegner S, Agan BK, Tasker SA, et al. (2006) Comparisons of causes of death and mortality rates among HIV-infected persons: analysis of the pre-early, and late HAART (highly active antiretroviral therapy) eras. J Acquir Immune Defic Syndr 41: 194-200.

4. Hellinger FJ (2007) The changing pattern of hospital care for persons living with HIV: 2000 through 2004. J Acquir Immune Defic Syndr 45: 239-246.

5. Cicalini S, Almodovar S, Grilli E, Flores S (2011) Pulmonary hypertension and human immunodeficiency virus infection: epidemiology, pathogenesis, and clinical approach. Clin Microbiol Infect 17: 25-33

6. Almodovar S, Hsue PY, Morelli J, Huang L, Flores SC; Lung HIV Study (2011) Pathogenesis of HIV-associated pulmonary hypertension: potential role of HIV1 Nef. Proc Am Thorac Soc 8: 308-312.

7. Estébanez-Muñoz M, Soto-Abánades Cl, Ríos-Blanco JJ, Arribas JR (2012) Updating our understanding of pulmonary disease associated with HIV infection. Arch Bronconeumol 48: 126-132.

8. Perello R, Miró O, Marcos MA, Bragulat E, Sánchez M, et al. (2008) Rentabilidad del cultivo de esputo en la consulta de urgencias de los pacientes infectados por el VIH y neumonía comunitaria. Emergencias 20: 256-259.

9. Adimora AA, Ramirez C, Auerbach JD, Aral SO, Hodder S, et al. (2013) Preventing HIV infection in women. J Acquir Immune Defic Syndr 63 Suppl 2 S168-173.

10. Instituto de Salut Carlos III (2008) Centro Nacional de Epidemiología-Ministerio de Sanidad y Consumo. Dirección General de Salud Pública. Secretaría del Plan Nacional sobre el SIDA. Mortalidad por VIH/SIDA en España año. Evolución de 1981-2008. Vigilancia epidemiológica del SIDA en España. Registro nacional de casos del SIDA. Actualización a mayo de 2010.

11. Fincher-Mergi M, Cartone KJ, Mischler J, Pasieka P, Lerner EB, et al. (2002) Assessment of emergency department health care professionals' behaviors regarding HIV testing and referral for patients with STDs. AIDS Patient Care STDS 16: 549-553.

12. Haukoos JS, Hopkins E, Bender B, Sasson C, Al-Tayyib AA, et al. (2013) Denver Emergency Department HIV Testing Research Consortium. Comparasion of enhanced targeted rapid HIV screening using the Denver HIV Risk Score Nontargeted rapid HIV Screening in the Emergency Department. Ann Emerg Med 61: 353-361.

13. White DA, Scribner AN, Martin ME, Tsai S (2012) A Comparison of Patient Satisfaction with Emergency Department Opt-In and Opt-Out Rapid HIV Screening. AIDS Res Treat 2012: 904916.

14. Jiménez S, Aguilò S, Gil V, Antolín A, Prieto S, et al. (2010) Psychosocial factors determine patients' acceptance of emergency department discharge directly to hospital-at-home care. Gac Sanit 24: 303-308.

15. CDC (1992) 1993 Revised Classification System for HIV Infection and Expanded Surveillance Case Definition for AIDS Among Adolescents and Adults.

16. Polo R, Pedrol E, Miró O; en representación del Grupo de expertos del documento de Consenso sobre Urgencias y VIH (2014) Human immunodeficiency virus and emergency departments. Reply. Enferm Infecc Microbiol Clin 32: 274-275.

17. Masiá M, Padilla S, Álvarez D, López JC, Santos I, et al. (2013) Risk, predictors and mortality associated with non-AIDS events in newly diagnosed HIV-infected patients: role of antiretroviral therapy. AIDS 27: 181-189.

18. Bartlett JG (2011) Diagnostic tests for agents of community-acquired pneumonia. Clin Infect Dis 52 Suppl 4: S296-304. 
Citation: Camón S, Perelló R, Escoda O, Escoda R, Aguilar N, et al. (2014) Reason for HIV Patients Consultation to the Emergency Department in the HAART Era: Incidence and Mortality. J AIDS Clin Res 5: 340. doi:10.4172/2155-6113.1000340

19. Joardar GK, Chatterjee C, Sadhukhan SK, Banerjee P, Dan A, et al. (2012) Screening of hospital patients for HIV: an experience in a tertiary care hospital of West Bengal. J Indian Med Assoc 110: 612-614, 622

20. Singer EJ, Valdes-Sueiras M, Commins DL, Yong W, Carlson M (2013) HIV stroke risk: evidence and implications. Ther Adv Chronic Dis 4: 61-70.

21. Becker AC, Sliwa K, Stewart S, Libhaber E, Essop AR, et al. (2010) Acute coronary syndromes in treatment-naïve black South africans with human immunodeficiency virus infection. J Interv Cardiol 23: 70-77.

22. Masiá M, Martínez E, Padilla S, Gatell JM, Gutiérrez F (2013) Endothelial function in HIV-infected patients switching from a boosted protease inhibitorbased regimen to raltegravir: a substudy of the SPIRAL study. J Antimicrob Chemother 68: 409-413.

23. Grivell R, Dodd J, Robinson J (2009) The prevention and treatment of intrauterine growth restriction. Best Pract Res Clin Obstet Gynaecol 23: 795807

24. Perelló R, Escoda O, Camón S, Miró O, Castañeda M, et al. (2014) Changes in the etiology, incidente and prognosis of acute lower respiratory track infections in HIV patients. Enferm Infecc Microbiol Clin.

25. Benito N, Moreno A, Miro JM, Torres A (2012) Pulmonary infections in HIVinfected patients: an update in the 21st century. Eur Respir J 39: 730-745.

26. Mohareb AM, Rothman RE, Hsieh YH (2013) Emergency department (ED) utilization by HIV-infected ED patients in the United States in 2009 and 2010 - a national estimation. HIV Med 14: 605-613.

27. Moreno S, del Romero J, del Amo J (2014) Human immunodeficiency virus infection in Spain: it is time to act. Enferm Infecc Microbiol Clin 32: 339-340.

28. Bozzette SA, Joyce G, McCaffrey DF, Leibowitz AA, Morton SC, et al. (2001) Expenditures for the care of HIV-infected patients in the era of highly active antiretroviral theraphy. HIV Cost and Services Utilization Study Consortium. N Engl J Med 344: 817-823.

29. Venkat A, Shippert B, Hanneman D, Nesbit C, Piontkowsky DM, et al. (2008) Emergency department utilization by HIV-positive adults in the HAART era. Int J Emerg Med 1: 287-296.
30. Josephs JS, Fleishman JA, Korthuis PT, Moore RD, Gebo KA, et al. (2010) Emergency department utilization among HIV-infected patients in a multisite multistate study. HIV Med 11: 74-84.

31. Gebo KA, Fleishman JA, Conviser R, Hellinger J, Hellinger FJ, et al. (2010) Contemporary costs of HIV healthcare in the HAART era. AIDS 24: 2705-2715.

32. O'Toole TP, Pollini R, Gray P, Jones T, Bigelow G, et al. (2007) Factors identifying-frequency and low-frequency health service utilization among substance-using adults. J Subst Abuse Treat 33:51-59.

33. Lacombe K, Rockstroh J (2012) HIV and viral hepatitis coinfections: advances and challenges. Gut 61 Suppl 1: i47-58.

34. De Mulder M, Holguín A (2013) Dried blood spots for monitoring HIV infection in Public Health Programs in developing countries. Enferm Infecc Microbiol Clin 31: 100-107.

35. Calderon $Y$, Leider J, Hailpern S, Haughey M, Ghosh R, et al. (2009) A randomized control trial evaluating the educational effectiveness of a rapid HIV posttest counseling video. Sex Transm Dis 36: 207-210.

36. Marco A, Gallego C, Blanco XR, Puig A, Argüelles MJ, et al. (2013) An analysis of adherence to the "Recommendations for the treatment of human immunodeficiency virus-infected adults" in a penitentiary in Barcelona. Enferm Infecc Microbiol Clin 31: 392-395.

37. Miró O, Antonio MT, Jiménez S, De Dios A, Sánchez M, et al. (1999) Decreased health care quality associated with emergency department overcrowding. Eur J Emerg Med 6: 105-107.

38. Nijhawan AE, Clark C, Kaplan R, Moore B, Halm EA, et al. (2012) An electronic medical record based model to predict 30 days risk of readmission and death among HIV-infected inpatients. J Acquir Immune Defic Syndr 61: 349-358.

39. Johnson BT, Michie S, Snyder LB (2014) Effects of behavioral intervention content on HIV prevention outcomes: a meta-review of meta-analyses. J Acquir Immune Defic Syndr 66 Suppl 3: S259-270.

40. Pericás JM, Aibar J, Soler N, López-Soto A, Sanclemente-Ansó C, et al. (2013) Should alternatives to conventional hospitalisation be promoted in an era of financial constraint? Eur J Clin Invest 43: 602-615. 